\title{
A new design algorithm for hybrid active power filter
}

\author{
Chau Minh Thuyen \\ Faculty of Electrical Engineering Technology, Industrial University of Ho Chi Minh City, Vietnam
}

\begin{tabular}{l} 
Article Info \\
\hline Article history: \\
Received Mar 3, 2019 \\
Revised Apr 17, 2019 \\
Accepted Jun 25, 2019 \\
\hline
\end{tabular}

\section{Keywords:}

Active power filter

Hybrid active power filter

Multi-objective optimization

Passive power filter

Social spider algorithm

\begin{abstract}
The correct determination of the parameters of Hybrid Active Power Filter (HAPF) plays a decisive role in its performance. Therefore, this paper proposes a new design algorithm for HAPF based on the Social Spider Algorithm (SSA). This algorithm has the advantage that it is possible to determine the parameters of both the power circuit part and the control circuit part of HAPF. The achieved results are multi-purpose, such as: minimum total harmonic distortion of the supply current and source voltage, the maximum reactive power compensation into the system and satisfy many constraints such as: system stability, resonance conditions of the branches and the limits of the parameters. Compared to traditional design method using the Particle Swarm Optimization algorithm, the proposed algorithm shows the advantages of smaller total harmonic distortion of supply current and source voltage, and higher reactive power compensation into the grid while still meeting the constraints.
\end{abstract}

Copyright $@ 2019$ Institute of Advanced Engineering and Science. All rights reserved.

\section{Corresponding Author:}

Chau Minh Thuyen,

Faculty of Electrical Engineering Technology,

Industrial University of Ho Chi Minh City,

12 Nguyen Van Bao Road, 4 Ward, Go Vap District, Ho Chi Minh City 700000, Vietnam.

Email: chauminhthuyen@iuh.edu.vn

\section{INTRODUCTION}

Today, more and more power electronic devices are connected to the electrical system, resulting in poor power quality. Accordingly, to improve the power quality, the Passive Power Filters (PPFs) [1] are connected in parallel with the load to suppress the harmonics generated by the nonlinear load. However, the PPF has the disadvantage that it is easy to resonate with the system impedance and the non-flexible compensation capability. Since then, the Active Power Filter (APF) was born [2], it is considered as a good solution for harmonic filtering and reactive power compensation. However, the APF also has the disadvantage of large investment costs, difficult to apply for high voltage grids. From the shortcomings of PPF and APF that Hybrid Active Power Filter (HAPF) was born as a necessity. HAPF is a combination of both PPF and APF, so it has both advantages of PPF and APF. The Hybrid Active Power Filter (HAPF) is considered as the most effective solution in harmonic filtering and reactive power compensation. However, the working efficiency of HAPF depends on many factors such as: correct determination of the parameters [3], control method [4-8], harmonic current detection method [9,10], control strategy [11] and stabilization of the DC-bus voltage for the inverter [12]. In which, the correct determination of the parameters of the HAPF is the most important factor, it decides the efficiency of harmonics filtering and reactive power compensation of HAPF.

The structure of HAPF consists of two parts: the power circuit part and the control circuit part. Until now, multi-objective optimization studies for the parameters determination of power circuit part can be summarized as follows: the application of Genetic Algorithm (GA) to multi-objective optimization design for passive power filters (PPFs) is proposed by [13]. However, the GA has the disadvantage of computationally expensive i.e. time-consuming. Another algorithm is also commonly used for HAPF design, called the Particle Swarm Optimization (PSO) algorithm. The PSO a lgorithm is used to design an APF in a 
four-wire three-phase system in case of balanced and unbalanced loads but only consider to design for PPFs and optimization for the APF but not for the HAPF [14-17]. Application of the bat algorithm to multiobjective optimization design of passive power filters set with time-varying inertia weights [18] and another study to multi-objective design on HAPF is using an ant colony algorithm [19] but only aslo multi-objective optimization design for PPFs. Ahmed Faheem Zobaa has used the Fortran Feasible Sequential Quadratic Programming algorithm to solve the multi-objective optimization problem for HAPF with the aim of finding PPF parameters [20].

In summary, the previous research on multi-objective optimization for HAPF was the only multi-objective optimization design of the power circuit part (parameters of the PPF). Meanwhile, the optimized design for the parameters of the control circuit part has not been studied and the calculation of the above parameters without considering the condition of the system stability.

To overcome this disadvantage, in this paper, the Routh's stability standard is used to check the stable condition of the HAPF system. Then a new multi-objective optimization design algorithm based on the Social Spider Algorithm (SSA) [21] is proposed to determine the best set of parameters for the HAPF. The proposed algorithm has the advantage of finding a quick solution with little loops and it can find all the parameters of both power circuit part and control circuit part. The results achieved will be global optimization such as the minimum of the total harmonic distortion of the source voltage and supply current, maximum reactive power compensation into grid in steady-state and satisfy the stable conditions.

The structure of the paper is divided into five parts. Part 1 is overview introduction of the issues that need to be investigated. The selected Hybrid Active Power Filter topology is presented in Part 2. Part 3 is multi-objective optimization algorithm for Hybrid Active Power Filter. The simulation results and discussion are presented in Part 4, and the conclusions are summarized in Part 5.

\section{THE SELECTED HYBRID ACTIVE POWER FILTER TOPOLOGY}

The selected Hybrid Active Power Filter topology is shown in Figure 1. It consists of five parts: $U_{s}$ and $Z_{s}$ are the source voltage and the resistance of the source. $C_{1}$ and $L_{1}$ are capacitance and inductance at the fundamental frequency. $C_{F}$ is the added capacitance to compensate reactive power. The transformer has ratio $1: 1$ to protect, insulate between the source and the voltage source inverter. $L_{0}$ is the output filter of the voltage source inverter. According to [3], the control block diagram of HAPF is shown in Figure 2.

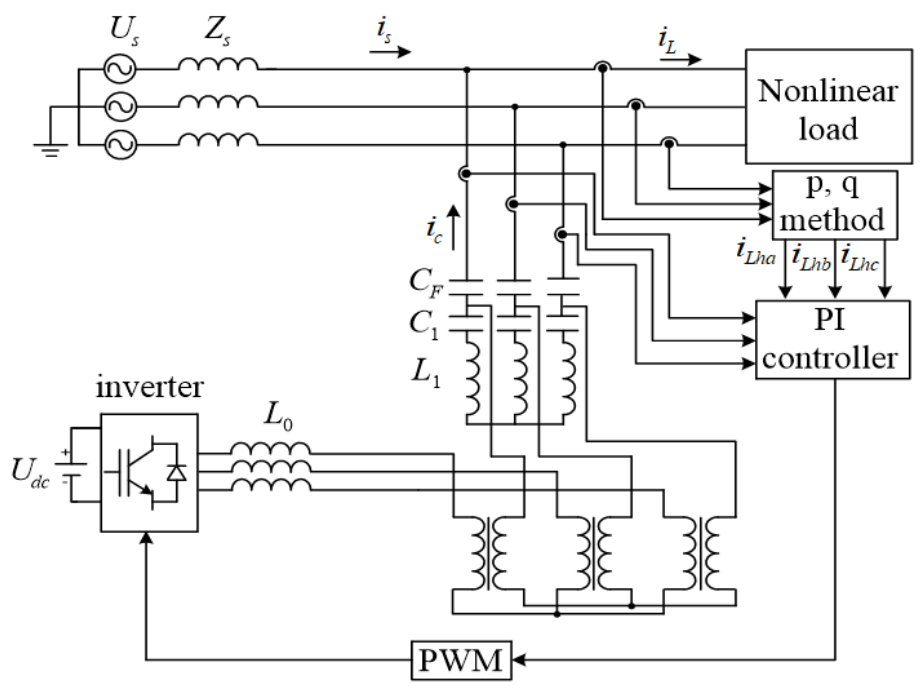

Figure 1. Topology of the hybrid active power filter

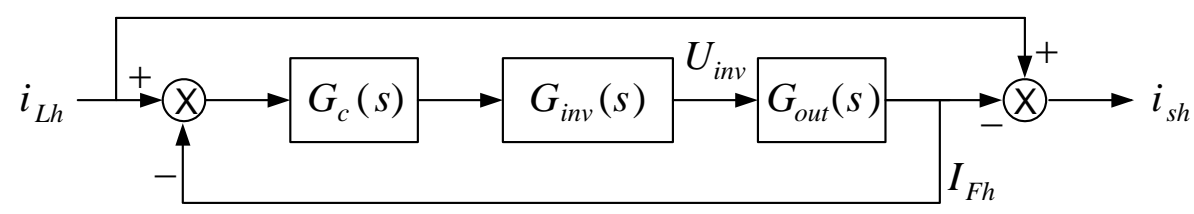

Figure 2. Control block diagram of HAPF 
From Figure 2, we have the transfer function of load harmonic current $I_{L h}$ to supply harmonic current $I_{s h}$ as:

$$
G(s)=\frac{I_{s h}}{I_{L h}}=\frac{1}{1+G_{c}(s) \cdot G_{i n v}(s) \cdot G_{\text {out }}(s)}
$$

Where: $G_{c}(s)$ is the transfer function of the tranditional PI controller, $G_{i n v}(s)$ is the transfer function of the inverter and $G_{\text {out }}(s)$ is the transfer function of the output circuit.

All of the above transfer functions are determinated according to [3]. The operating principle of HAPF control circuit is also based on the load current: the load current $i_{L}\left(i_{L a}, i_{L b}\right.$, $\left.i_{L c}\right)$ will be separated the harmonic component of the load current as $i_{L h a}, i_{L h b}, i_{L h c}$. These components will be chosen as the reference components and they are compared to the compensate current components into the grid $i_{c}$ of HAPF are $i_{c a}, i_{c b}$ and $i_{c c}$. The error of the above comparison will be taken through the PI (Proportional Integral) controller, through pulse width modulation to control ON-OFF switches of the inverter to generate compensate signals on the grid.

The parameters need to be determined in the model in Figure 1 including: passive circuit $C_{F}-C_{l}$ $L_{l}$, output filter $L_{0}$, voltage bus-DC of inverter $U_{d c}$, parameters of PI controller are $K_{p}$ and $K_{i}$. Currently, these parameters are usually determined based on experience and local calculations, regardless of the stability of the system. Therefore, this paper proposes a new multi-objective optimization algorithm that has considered to the stability of the system.

\section{NEW MULTI-OBJECTIVE OPTIMIZATION DESIGN ALGORITHM FOR HYBRID ACTIVE POWER FILTER}

\subsection{Constraints and objective function}

When design a HAPF system, all of the following constraints need to be considered:

+ System stability constraint:

From (1), we have the characteristic equation of the control transfer function as follows:

$$
D(s)=a_{6} s^{6}+a_{5} s^{5}+a_{4} s^{4}+a_{3} s^{3}+a_{2} s^{2}+a_{1} s^{1}
$$

According to Routh's stability standard, following conditions must be satisfied.

$$
\left\{\begin{array}{l}
a_{5} a_{4}-a_{6} a_{3}>0 \\
a_{3} a_{2}-a_{4} a_{1}>0 \\
b_{1} a_{3}-a_{5} b_{3}>0 \\
b_{2} b_{3}-b_{1} b_{4}>0 \\
a_{1} b_{3} \quad>0
\end{array}\right.
$$

With: $b_{1}=\frac{a_{5} a_{4}-a_{6} a_{3}}{a_{5}} ; b_{3}=\frac{a_{3} a_{2}-a_{4} a_{1}}{a_{3}} ; b_{2}=\frac{b_{1} a_{3}-a_{5} b_{3}}{b_{1}} ; b_{4}=\frac{b_{3} a_{1}}{b_{3}} ; c_{1}=\frac{b_{3} b_{2}-b_{1} b_{4}}{b_{2}} ; c_{2}=b_{4}$;

$$
\begin{aligned}
a_{6}= & T_{i} T L_{1} C_{1} C_{F}\left(L_{1} L_{s}+L_{1} L_{0}+L_{1} L_{0} L_{s}\right) ; a_{5}=T_{i} T\left(R_{s} L_{1} C_{1} C_{F}+R_{s} L_{0} C_{1} C_{F}\right)+T_{i}\left(C_{1} C_{F} L_{1} L_{s}+L_{1} L_{0} C_{1} C_{F}+C_{1} C_{F} L_{0} L_{s}\right) ; \\
& \left.a_{4}=T_{i} T\left(L_{0} C_{F}+L_{s} C_{F}+L_{1} C_{1}+L_{0} C_{1}\right)+T_{i}\left(R_{s} L_{1} C_{1} C_{F}+R_{s} L_{0} C_{1} C_{F}\right)+C_{F} C_{1} L_{1} K_{i n v} K T_{i}\right) \\
& a_{3}=T_{i} T C_{F} R_{s}+T_{i}\left(L_{0} C_{F}+L_{s} C_{F}+L_{1} C_{1}+L_{0} C_{1}\right)+K K_{i n v} C_{1} L_{1} C_{F} ; a_{2}=T_{i} T+T_{i} C_{F} R_{s}+T_{i} K K_{i n v} C_{F} \\
& a_{1}=T_{i}+K K_{i n v} C_{F} ; T=0.01 m s ; T_{i}=0.00001 ; K=10 ; K_{i n v}=1
\end{aligned}
$$

Where $K_{i n v}$ is inverter gain, $T$ is time constant, $K$ is proportional coefficient, $T_{i}$ is integral constant.

- Constraints on resonance conditions in PPFs: The $L$ and $C$ parameters in a branch must be resonated at a certain frequency.

$$
\omega_{n} L=\frac{1}{\omega_{n} C}
$$

- Constraint of passive power filter values: passive power filter values must be positive and meet system stability and resonance conditions. 


$$
0<\left(R_{i}, L_{i}, C_{i}\right) \leq\left(R_{\max }, L_{\max }, C_{\max }\right)
$$

The values of $R_{\max }, L_{\max }$ and $C_{\max }$ are determined under stable conditions (2).

- PPFs must be compensated with a maximum capacity but not exceed the required maximum limit

$$
Q_{c \min } \leq Q_{c} \leq Q_{c \max }
$$

- Constraint of DC-bus voltage value:

$$
0<U_{d c}<U_{d c-\max }
$$

- Controller parameters constraints: Controller parameters must be positive and satisfy system stability conditions (3).

$$
0<K_{p}<K_{\text {pmax }} ; 0<K_{i}<K_{\text {imax }}
$$

According to [8], the value of $K_{p}$ and $K_{i}$ is too small or too large to cause system instability.

- Objective function: Here we consider the three main objectives are: $\min T H D i_{s}, \min T H D u_{s}$ and $\max Q_{c \Sigma}$.

We transfer three objectives problem to single objective problem by the following fomular:

$$
F=\min \left(T H D i_{s}+T H D u_{s}+1 / Q_{c \Sigma}\right)
$$

According to IEEE Std. 519-1992 Recommended Practices and Requirements for harmonic control in electrical power systems [22], then total harmonic distortion (THD) of current is less than or equal $5 \%$. THD of supply voltage at point of common coupling is less than or equal $5 \%$ and $Q_{c \Sigma}$ is determined based on the load.

\subsection{Social spider algorithm and its application to hybrid active power filter design}

In order to design a Hybrid Active Power Filter system, a new multi-objective optimization algorithm based on Social Spider Algorithm (SSA) is proposed. In SSA [21], the solution of the SSA is simulated by an artificial spider's position on a spider web. Spiders in a population (pop) move on the web and share location information through its vibration. Depending on the vibration received from the spiders, it will direct the spiders to the optimal position. Artificial spiders are a major factor in the SSA algorithm. Each spider possesses a location on the spider web map and the most appropriate value of the position is located on the spider map. Each spider occupies the best state, including: current position, current value, vibration intensity, pitch, previous action and the size of the spider. All of these characteristics will direct the spider to find the optimal solution. In each iteration, all spiders on the web move to a new position and evaluate their fitness values. The algorithm first calculates the fitness values of all the artificial spiders on different positions on the web. Then these spiders generate vibrations at their positions using the following equation.

$$
I\left(P_{s}, P_{s}, t\right)= \begin{cases}1 /\left(C_{\max }-f\left(P_{s}\right)\right) & \text { for maximization } \\ 1 /\left(f\left(P_{s}\right)-C_{\min }\right) & \text { for minimization }\end{cases}
$$

Where $C_{\max }$ is a confidently large constant selected such that all possible fitness values of the maximization problem is smaller than $C_{\max }, C_{\min }$ is a confidently small constant such that all possible fitness values of the minimization problem is larger than $C_{\min }, I\left(P_{s}, P_{s}, t\right)$ is intensity of the vibration generated by spider $s$ at the source position, $f\left(P_{s}\right)$ is fitness of the position of spider.

After all the vibrations are generated, the algorithm simulates the propagation process of these vibrations using the following equation.

$$
I\left(P_{a}, P_{b}, t\right)=I\left(P_{a}, P_{a}, t\right) \cdot \exp \left(-\frac{D\left(P_{a}, P_{b}\right)}{D_{\text {max }} \cdot r_{a}}\right)
$$

Where $D\left(P_{a}, P_{b}\right)$ is distance between spider $a$ and $b, D_{\max }$ is maximum distance between two points in the search space and $r_{a} \in(0,1)$. 
In this process, each spider $s$ will receive $(p o p-1)$ different vibrations generated by other spiders. Each spider $s$ will select the strongest vibration $v_{\text {best }}$ from $(s-1)$ spiders and compare its intensity with the intensity of the target vibration $v_{\text {tar }}$ stored in its memory. $s$ will store $v_{\text {best }}$ as $v_{\text {tar }}$ if the intensity of $v_{\text {best }}$ is larger, otherwise the original $v_{\text {tar }}$ is retained. The algorithm then manipulates $s$ to perform a random walk towards $v_{t a r}$. The algorithm repeats this process for all the spiders in pop. To avoid SSA getting stuck in a local optimum, each spider in pop, right after the random walk step, has a small probability to decide not to follow its present target and jump away from its current position.

Flowchart of multi-objective optimization algorithm based on SSA for HAPF shown in Figure 3 (appendix). Begin, we enter the upper and lower limits of the parameters $C_{F}, C_{l}, L_{l}, L_{0}, U_{d c}, K_{p}$ and $K_{i}$, then the SSA algorithm begins by creating the original dataset of $C_{F}, C_{1}, L_{1}, L_{0}, U_{d c}, K_{p}$ and $K_{i}$. This dataset will be checked for stability of the system, if it does not meet the stability condition, the system will return to create a new data set, if it satisfies the stable condition of the system, then these parameters will be estimated by the fitness function corresponding to the current position of the spiders on the spider web, and then the spiders will create vibration. The spiders will propagate and select vibration. If this vibration is stronger than the previous target the spider will use the selected best vibration as the new target, otherwise attenuate the previous target vibration. Based on the vibration from the spiders it will direct the spiders to a better position. This new position will be compared to the objective function, if satisfied, then stop and print the best result set, otherwise return to the create an original dataset.

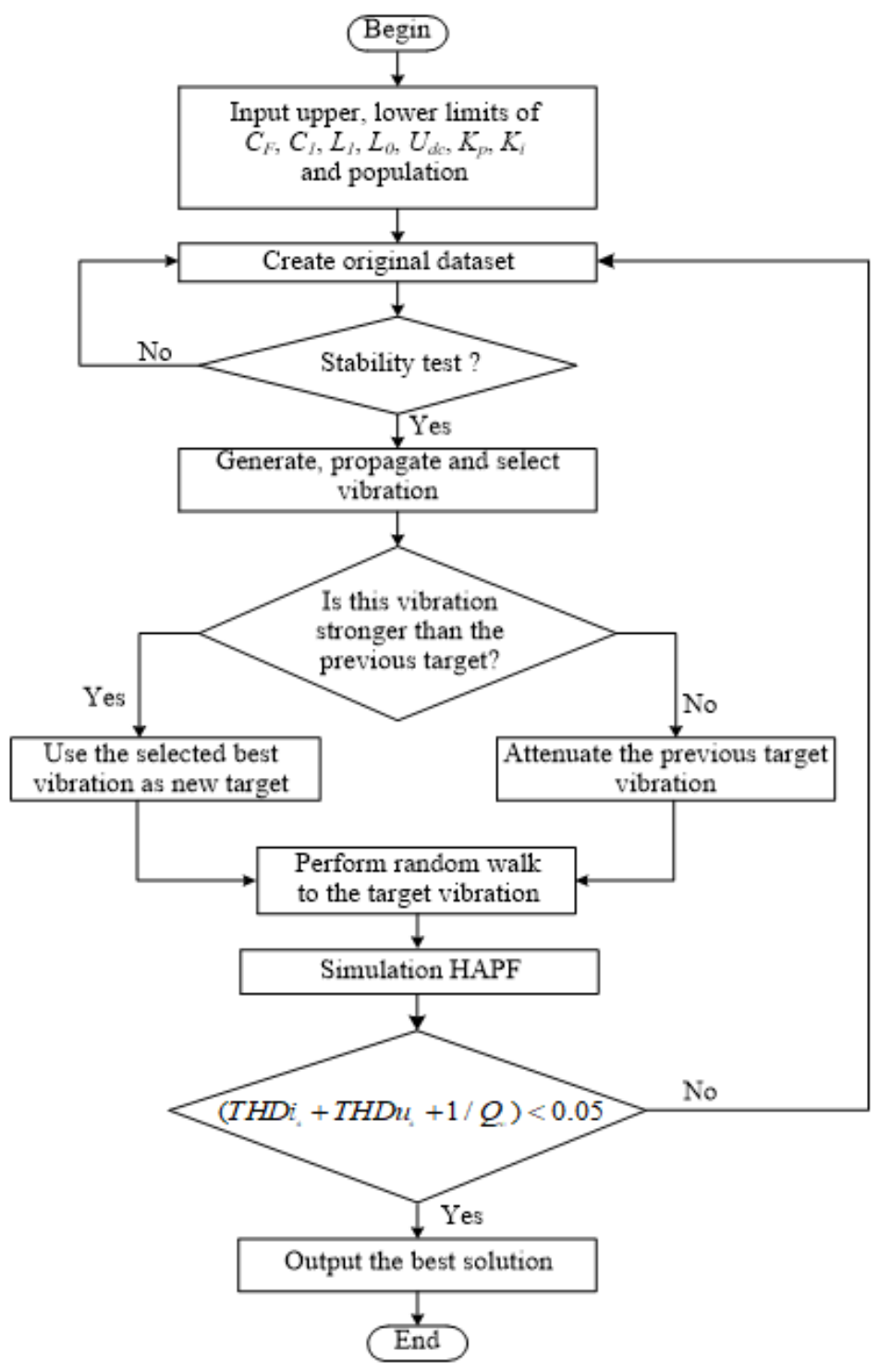

Figure 3. Flowchart of new multi-objective optimization design algorithm for HAPF 


\section{SIMULATION RESULTS AND DISCUSSION}

To compare the effectiveness between the proposed design algorithm and traditional design. Let us consider a HAPF model as shown in Figure 1. Three-phase source voltage is $380 \mathrm{~V}-50 \mathrm{~Hz}$. Nonlinear load is built by three-phase uncontrolled bridge rectifier with load $R_{L}=3 \Omega, L_{L}=0.3 \mathrm{mH}$. THD of the load current is shown in Figure 4. The calculation of HAPF parameters is done in two ways: the first way is to calculate according to the traditional design using PSO algorithm and the second way is to calculate the proposed algorithm.

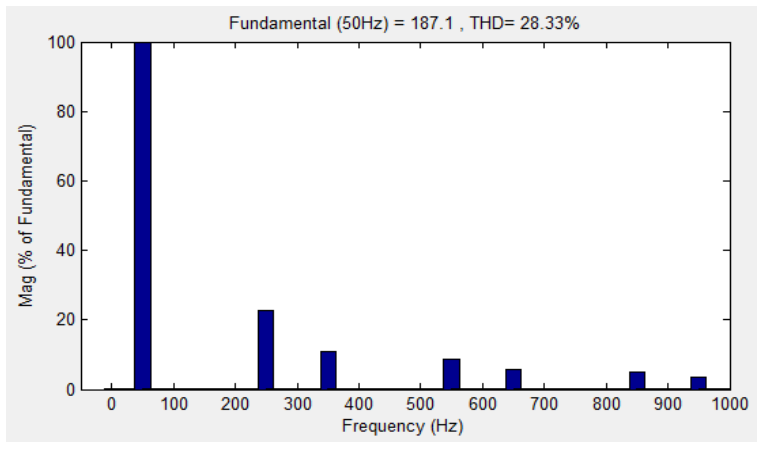

Figure 4. THD of the load current

With the traditional design method using the PSO algorithm, the parameters of the HAPF system after 100 iterations are summarized in Table 1. Accordingly, the defined parameters only include the parameters of the power circuit part are $C_{F}, C_{l}, L_{1}$ and $L_{0}$.In addition, the controller parameters are randomly selected with the best parameters of $K_{p}=30$ and $K_{i}=0.1$, switching frequency $f=10 \mathrm{kHz}$ and DC-bus voltage is $600 \mathrm{~V}$.

Table 1. HAPF parameters by traditional design method

\begin{tabular}{ccccccc}
\hline $\begin{array}{c}C_{F} \\
(\mu \mathrm{F})\end{array}$ & $\begin{array}{c}C_{l} \\
(\mu \mathrm{F})\end{array}$ & $\begin{array}{c}L_{l} \\
(\mathrm{mH})\end{array}$ & $\begin{array}{c}L_{0} \\
(\mathrm{mH})\end{array}$ & $\begin{array}{c}U_{d c} \\
(\mathrm{~V})\end{array}$ & $K_{p}$ & $K_{i}$ \\
\hline 117.27 & 479.83 & 21.83 & 1.83 & 600 & 30 & 0.1 \\
\hline
\end{tabular}

From the parameters in Table 1, we obtain the waveforms of the HAPF system shown in Figure 5. From Figure 5, we see that: THD of the supply current $i_{s}$ decreases from $28.33 \%$ to $2.32 \%$, THD of the source voltage $u_{s}$ is $2.04 \%$, while the reactive power decreased to 740var from 3005var, that is, the capacity compensated by PPFs is 2265var. THD of the supply current $i_{s}$ shown in Figure 6 . THD of the source voltage $u_{s}$ is shown in Figure 7. With the proposed algorithm, the best parameters of both the power circuit part and control circuit part after 50 iterations are shown in Table 2.
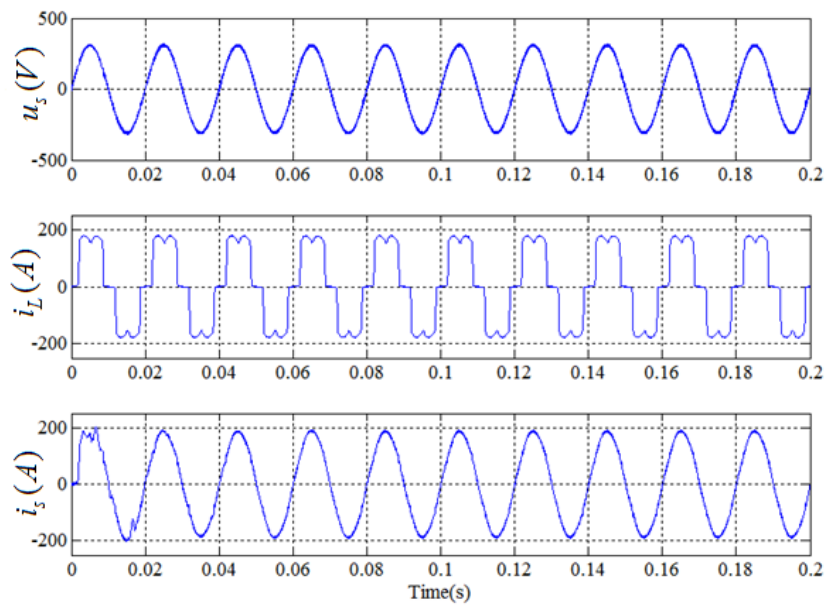

Figure 5. Waveforms of HAPF with traditional design using PSO 


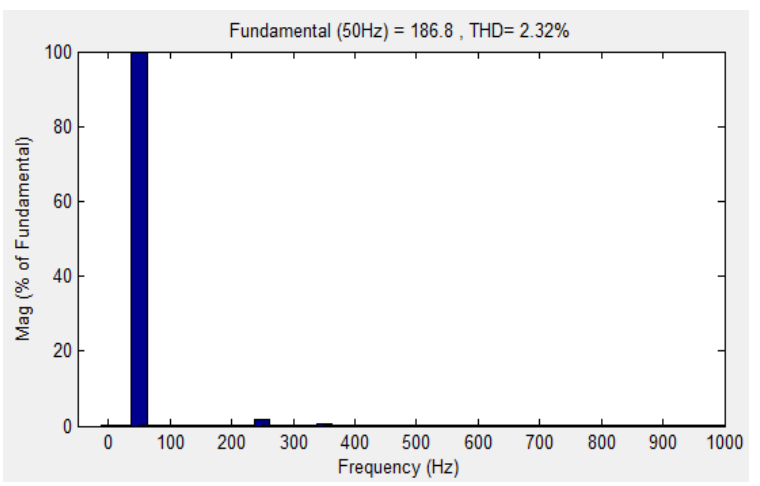

Figure 6. THD of the supply current $i_{s}$

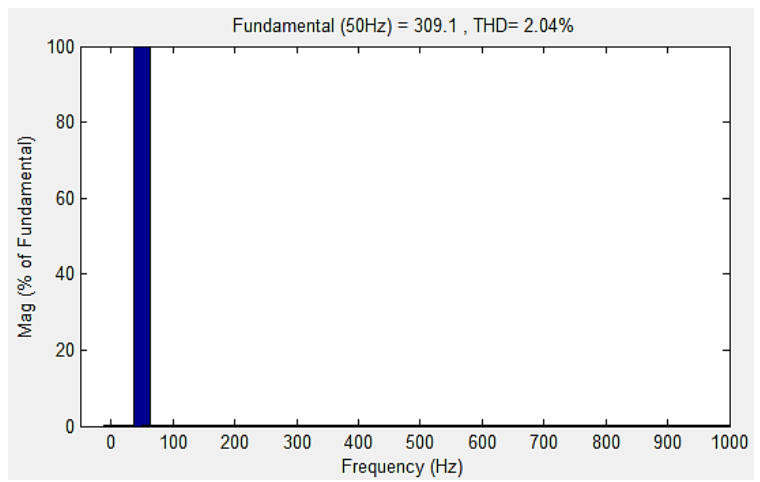

Figure 7. THD of the source voltage $u_{s}$

Table 2. HAPF parameters with the proposed multi-objective optimization design algorithm

\begin{tabular}{ccccccc}
\hline $\begin{array}{c}C_{F} \\
(\mu \mathrm{F})\end{array}$ & $\begin{array}{c}C_{l} \\
(\mu \mathrm{F})\end{array}$ & $\begin{array}{c}L_{l} \\
(\mathrm{mH})\end{array}$ & $\begin{array}{c}L_{0} \\
(\mathrm{mH})\end{array}$ & $\begin{array}{c}U_{d c} \\
(\mathrm{~V})\end{array}$ & $K_{p}$ & $K_{i}$ \\
\hline 119.53 & 339.978 & 30.849 & 0.193 & 662.061 & 32.118 & 0.699 \\
\hline
\end{tabular}

From the parameters in Table 2, we obtain the waveforms of the HAPF system shown in Figure 8. From Figure 8, we can see that: THD of the supply current $i_{s}$ decreases from $28.33 \%$ to $1.72 \%$, THD of the source voltage $u_{s}$ is $1.36 \%$ while the reactive power decreased to $700 \mathrm{Var}$ from $3005 \mathrm{Var}$, so the compensation power by PPFs is 2305Var, THD of the supply current $i_{s}$ in steady-state is shown in Figure 9, THD of the source voltage $u_{s}$ in steady-state is shown in Figure 10.
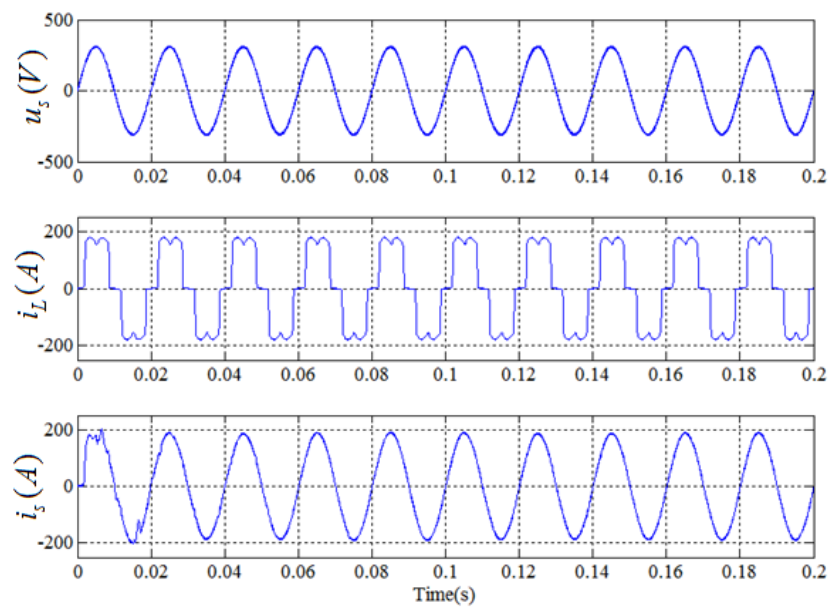

Figure 8 . The waveforms of HAPF with the proposed algorithm

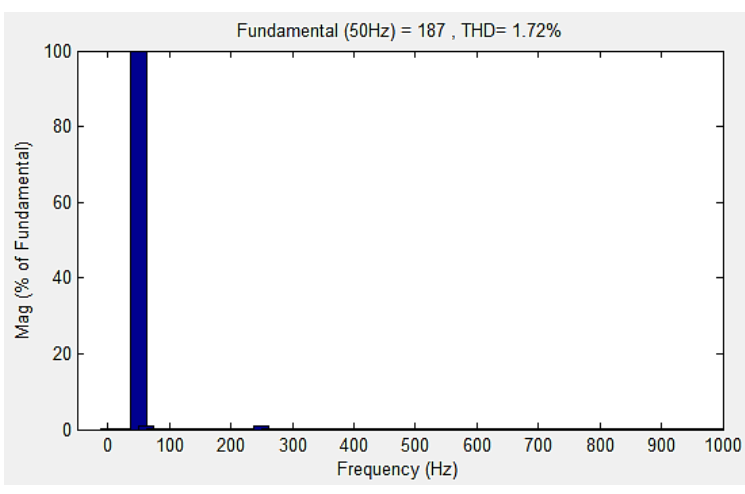

Figure 9. THD of the supply current $i_{s}$

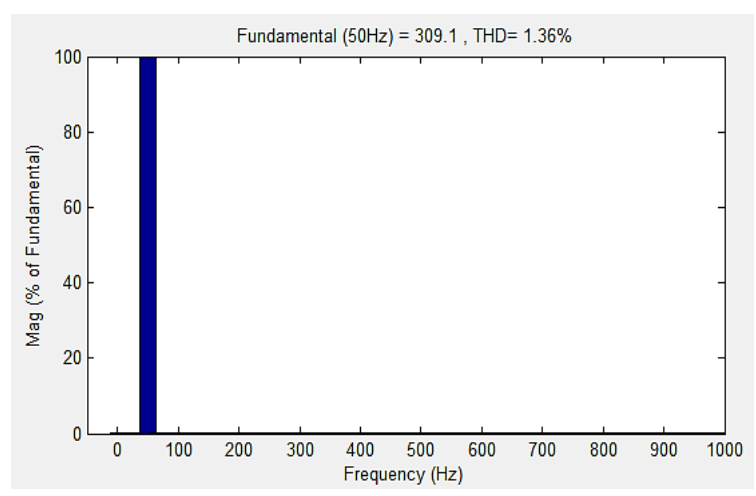

Figure 10.THD of the source voltage $u_{s}$ 
From the above analysis, we can see that: the proposed algorithm is more effective than the traditional design in reducing the total harmonic distortion and the maximum reactive power compensate into the grid in steady-state and meet IEEE Std. 519-1992.

\section{CONCLUSION}

The paper has provided a new multi-objective optimization design algorithm for HAPF. This algorithm can determine the parameters of both the power circuit part and the control circuit part of HAPF. The achieved results are multi-purpose, such as: minimize the total harmonic distortion of the supply current and source voltage, maximize the reactive power compensation into the grid and satisfying many constraint conditions, such as: system stability, resonance conditions, passive power filter values, DC-bus voltage value and controller parameters constraints. This research can be applied to design for all different types of HAPF.

\section{ACKNOWLEDGEMENTS}

This work is partial supported by the scientific research subject No. 5048/QĐ-BCT of the Ministry of Industry and Trade of the socialist republic of Viet Nnam with the title: "Research, design and manufacture three-phase active compensation model with $5 \mathrm{~kW}$ capacity for harmonic filtering of nonlinear loads".

\section{REFERENCES}

[1] Amol Anandrao Patil, et al., "Harmonic metigation using passive filter," International Journal of Engineering Trends and Technology, vol. 45, pp. 83-86, 2009.

[2] C. Madtharad and S. Premrudeepreechacharn, "Active power filter for three-phase four-wire electric systems using neural networks," Elect. Power Syst. Res., vol. 60, pp. 179-192, 2002.

[3] Chau Minh Thuyen, "A new approach in design for hybrid active power filter," ICIC Express letters, vol. 12, pp. 897-904, 2018.

[4] C. Madtharad and S. Premrudeepreechacharn, "Active power filter for three-phase four-wire electric systems using neural networks," Elect. Power Syst. Res., vol. 60, pp. 179-192, 2002.

[5] M. Chau, et al., "Online control method with time-delay compensation for hybrid active power filter with injection circuit," IET Power Electronics, vol. 5, pp. 1472-1482, 2012.

[6] Minh Thuyen Chau, "Adaptive current control method for hybrid active power filter," Journal of Electrical Engineering, vol. 67, pp. 343-350, 2016.

[7] An Luo, et al., "Development of hybrid active power filter based on the adaptive fuzzy dividing frequency-control method," IEEE Transactions on Power Delivery, vol. 24, pp. 424-432, 2009.

[8] Z. Shuai, A. Luo, C. Tu, D. Liu, "New control method of injection-type hybrid active power filter," IET Power Electronics, vol. 4, pp. 1051-1057, 2011.

[9] Chau Minh Thuyen, "Improved p-q Harmonic Detection Method for Hybrid Active Power Filter," International Journal of Electrical and Computer Engineering (IJECE), vol. 8, no. 5, pp. 2910-2919, 2018.

[10] H. Akagi, et al., "Generalized theory of instantaneous reactive power and its application," Electrical Engineering of Japan, vol.103, pp. 483-490, 1983

[11] Y. K. Latha, et al., "Control strategy for three phase shunt active power filter with minimum current measurements," International Journal of Electrical and Computer Engineering (IJECE), vol. 1, no. 1, pp. 31-42, Oct 2011.

[12] An Luo, et al., "Design considerations for maintaining DC-side voltage of hybrid active power filter with injection circuit," IEEE Transactions on Power Electronics, vol. 24, pp. 75-84, 2009.

[13] C. C. M. Moura, et al., "Determination of the R-L-C parameters of a passive harmonic filter using genetic algorithm," in $10^{\text {th }}$ International conference on harmonics and quality of power, 2002, pp. 495-500.

[14] Suresh kumar, Ramesh reddy and Archana, "The application of pso to hybrid active power filter design for 3 phase 4-wire system with balanced \& unbalanced loads," International journal of advances in engineering \& technology, vol. 2, pp. 32-42, 2012.

[15] N. S. Hasan, et al., "Harmonic Suppression of Shunt Hybrid Filter using LQR-PSO based," International Journal of Electrical and Computer Engineering (IJECE), vol. 7, no. 2, pp. 869-876, 2017.

[16] Shengqing Li, et al., "Multi-objective optimal design for passive power filters in hybrid power filter system based on multi-island particle swarm optimization," in 7th International Conference on Power Electronics and Motion Control, pp. 2859-2863, 2012.

[17] Suresh kumar and K. Ramesh, "The application PSO hybrid active power filter design for 3phase 4-wire system with variable load," International journal of engineering inventions, vol. 1, pp. 39-46, 2012.

[18] Nien-Che Yang and Minh-Duy Le, "Multi-objective bat algorithm with time-varying inertia weights for optimal design of passive power filters set," IET Generation, Transmission \& Distribution, vol. 9, pp. 644-654, 2015. 
[19] Rrachid Dehini and Slimane Sefiane, "Power quality and cost improvement by passive power filters synthesis using ant colony algorithm," Journal of theoretical and applied information technology, vol. 1, pp. 70-79, 2012.

[20] Ahmed Faheem Zobaa, "Optimal multi-objective design of hybrid active power filters considering a distorted environment," IEEE transactions on industrial electronics, vol. 61, pp. 107-114, 2014.

[21] James J.Q. Yu, et al., "A social spider algorithm for global optimization," Technical Report No. TR-2003-004, Dept. of Electrical \& Electronic Engineering, the University of Hong Kong, pp. 1-16, 2013.

[22] IEEE Std. 519-1992. IEEE Recommended Practices and Requirements for Harmonic Control in Electrical Power Systems, 1993.

\section{BIOGRAPHIES OF AUTHORS}

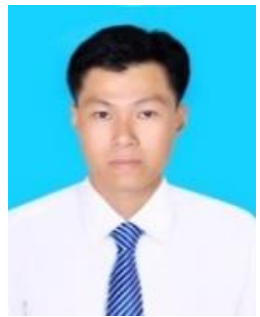

Chau Minh Thuyen was born in Binh Dinh, Vietnam, on June 6, 1977. He received his B.S. and M.S. from the Da Nang University of Technology, Da Nang, Viet Nam, and the University of Technical Education Ho Chi Minh City, Ho Chi Minh City, Viet Nam, in 2001 and 2005, respectively, and Ph.D. from Hunan University, Changsha, China, in 2012., Since 2004, he has been a Lecturer at Industrial University of Ho Chi Minh City, Viet Nam. His current research interests include electric power savings, reactive power compensation, and active power filters. 